\title{
The Application of Task-based Approach in College English Writing Teaching
}

\author{
Xiaogang Jia \\ Xijing University, Xi’an, Shaanxi, China, 710123 \\ jiaxiaogang@126.com
}

Keywords: task-based approach, college English writing, application research

\begin{abstract}
As the first foreign language in Chinese educational environment, the impact of English on the future development of students is enormous. College English writing teaching is the only one teaching link to cultivate students' English writing ability, which is essential for the cultivation of students' English writing ability. In order to cultivate students 'English writing literacy, more and more teaching methods have been applied. As one of the most representative teaching methods, task-based teaching method has made great contribution to the improvement of students' English writing ability. In order to play the role, it must have a deeper study and discussion on the application of the task based teaching in college English writing teaching.
\end{abstract}

\section{Introduction}

It is widely acknowledged that writing, as one form of language output, occupies an important and indispensable position in human communication. To fulfill the requirements, linguists and scholars attach more importance to improve students' English writing effectively, and the writing teaching methods, such as the product approach, process approach, genre approach have been evolved. The traditional product teaching approach which puts emphasis on the final product has dominated the field of English writing teaching for a long time and it has contributed a lot to reinforce students' linguistic knowledge on grammar and sentence structures, which are the basic elements of writing a good composition. However, it is a pity that it excessively stresses the grammar and sentence patterns, neglecting the writing content and students' learning attitude and performance. The process teaching approach to English writing leaves students full room for creativity and imagination on the writing topic. However, the effect is not obvious to Chinese English learners since it is advanced to meet the writing requirements of students whose mother tongue is English. The genre approach helps students be familiar with various genres, while the prescriptive nature of which makes the writing class stereotyped and students' hold inactive attitude to writing. As the proverb says attitude is everything", the negative attitude hinders the development of students' language learning ability. In such a case, students' writing proficiency and writing skills are being at a standstill. Consequently, various problems have turned up in students' English writing, such as devoid of content, stereotyped text organization, ungrammatical sentences, spelling errors and so on.

\section{Theories Concerning about Task and Task-based Language Teaching}

What is a task? There is no widely accepted definition of the task since researchers off explanations from different perspective. As the founder of task-based language teaching, N. S. Prabhu defines it that "a task is an activity which requires learners to arrive at an outcome from given information through some processes of thoughts, and which allows teachers to control and regulate that process."He clarifies that the task is goal-oriented, and students and teachers have their own responsibilities during the process. Jane Willis in her book A Framework for Task-based Learning, defines it that "Tasks are activities where the target language is used by learners for a communicative purpose in order to achieve an outcome."Nun an defines it from the communicative perspective, that is "a task is a communicative classroom activity, within which the learners interact and convey meaning in the target language, focusing on the fluency of meaning rather than the 
accuracy of form." What is more, Nun an divides the task into two type, one type is target tasks or the real-world tasks, just as the definition of task that Long(1985) has defined "a task is a piece of real-life work, such as painting the fence, ordering an airline ticket, filling out a table..."; another type is the pedagogical tasks, namely, the classroom activities, such as group discussion, through which the learners' comprehensive competence in the target language will be improved.

Different people hold different opinions about the definitions of the task, similarly, they have different opinions on the elements of composing a task.

Input refers to data that forms the point of departure for the task. Moreover, target language exposure should be close to the real-life, either verbal (weather report, travelling guide) or nonverbal(diagram, photograph, traffic map). Sufficient language exposure ensures the proceeding of the tasks.

Learners and teachers' role. One typical feature of task-based language teaching is that it focuses on students' performance in the classroom learning. In this sense, the learners' role should be paid more attention to. Therefore, group work, peer evaluation and cooperative learning should be encouraged in the process of implementing the tasks. Besides, teachers play multi-functional roles in the whole teaching process, and the roles are changing with the progressing of the tasks, such as resource-providers in the pre-task stage, facilitators and participants in the stage of task cycle, and so on.

Task-based language teaching is, in fact, a further development of communicative language teaching. As a new type of teaching method, it is in pursuit of transforming the basic theories of language application into practical and meaningful classroom language teaching, which embodies the new teaching concept of "learning by doing". Briefly, learning by doing means that students naturally possess the ability of using the target language flexibly in social context through transacting the tasks. On the other hand, it puts emphasis on meaningful communication in the teaching process. Here, communication is not a simply cycle of questions and answers, but a transacting, expressing and explaining process. It tries to turn the language learner into the language user.

\section{Types of College English Writing in China}

In order to help our college students to improve their writing ability, we should analyze the types and limitations of college English writing in our country, and find a better and more effective writing teaching method.

(1) training (2) imitation; (3) the training of students to learn; (4) Communication (5) fluency and (6) learning. According to Raimes point of view, the current form of college English writing in China are the following four categories:

Consolidated writing: This type of writing mainly consolidates the learned phrases and sentences, emphasizing their correct use and memory, therefore, require students to do a lot of practice, such as the sentence into a sentence, continued sentence, sentence conversion. These exercises focus on grammatical forms without emphasizing content and meaning.

Exercising writing: This type focuses on the sentence level above the level of training. Teachers have strict control and guidance on the linguistic form of writing, which requires the use of appropriate words, correct grammar, and attention to the connection between sentence and sentence. The main exercises are: to reorganize the order by disrupting the logic of the sentence; in the paragraph to delete or add words; find the topic sentence of the paragraph, and that the theme of writing methods; with the appropriate means of connecting sentences into paragraphs. This kind of writing mainly focuses on word selection and grammatical structure, and has less consideration on meaning, style and register.

Mimetic writing: This type of writing is intended to enable students to use the selected essay or prescribed tips for writing. The method is to provide a model essay, analyze its language features and text structure, so that students are familiar with certain syntax and rhetorical devices, and then write a theme similar to the composition; or provide an outline or a number of tips for students to follow the prompts to write. This type of writing can help students understand and become familiar 
with foreign language writing techniques, for example, how to use time and space sequences, causation, comparison techniques to expand the theme of paragraphs or essays. Such writing on the content, rhetoric has a certain attention, but the focus is still the structure and language accuracy, not the real written communication.

Communicative Writing: This type of writing puts not too much emphasis on the accuracy of language, but pay attention to why write and for whom to write, that is, it is necessary to emphasize the purpose of writing the writer, but also consider whether readers understand the article and the expression of the content. Nystrand pointed out that: Many of the obvious features of written communication are not in the article itself, nor in the communication between the reader and the article, but in the author and readers of the exchange. So writing is no longer infinite, no longer writing for writing, it is to a certain extent, attention to the reader's feedback. However, this kind of writing has not received enough attention in some universities in China, because there are still many difficulties in the teaching practice, such as students' language foundation is not solid, poor foundation, can not use foreign languages to express their true thoughts correctly.

\section{The Specific Strategies of Task -based Teaching}

Pre-writing task is to provide teachers with specific goals and significance of the writing task to enable students to complete the writing task. At present, the types of college English writing tasks can be divided into reading summary or impression, bibliography, experience reports, theoretical research reports, case studies, comprehensive data and research and test several major types. Teachers in the pre-writing task arrangement, it should pay attention to do a good job in all aspects of the integrated control to be able to better stimulate the interest of students writing to achieve writing teaching objectives. For example, in order to stimulate interest in the writing of students, teachers can be arranged for students to personal resume or experimental report writing task, because students with their own life-related and practical hands involved in the writing task has a very large interest, and this is also in line with teaching Link between the authenticity and practicality. It should be noted that in the early task arrangement, teachers need to frequently transform the task context and task content, because different tasks can provide students with different forms of language to stimulate different background knowledge and language information, in the classroom to provide students with different Of the task environment, so that they can use their own English language skills. After selecting a good task, teachers should provide students with a few real model essays and with the students to analyze them, so that students master the right points of the writing of the right.

Students begin to write until writing is completed and the task is teaching the teaching of the intermediate links. In this session, students in accordance with the pre-writing tasks in the layout of the text and the teacher given the prompts to complete the writing within the specified time content. On this basis, the teacher will be divided into several groups of students to form a fixed writing discussion group, so that they want to carry out the content of writing to explore and plan to jointly prepare the first draft of the paper for the preparation of the latter part of the report. For the groups to be discussed, teachers need to be clear when the group is to explore the specific issues are as follows:

I want to write what?

What is the goal?

How much do you want to know the topic?

What are you interested in the topic?

What is the most important in this topic?

After the discussion between the members of the group, you can help students to write between the purpose of writing, ideas and methods of sharing and communication. After writing, each group sent a representative to report the results of their discussion, in order to achieve teaching effectiveness reports should be used in English, in addition to the contents of the above to include the above and we must also pay attention to the accuracy of writing language and Fluency. 


\section{Conclusion}

When the student completes the writing and reporting, the task-based teaching method can enter the later stage of analysis and discussion. The goal of this part is to enable the students to have a correct and proper understanding of their writing tasks and to analyze and explore knowledge, to achieve the level of English writing. In this session, the teacher must first of all make evaluation analysis for all groups of the report. The content of the analysis can be the theme of the article, it can be argument, the purpose is to encourage students, while pointing out the shortcomings of students in the writing process and it is designed to enhance students' practical writing skills. In this session, in order to enable students to better understand their writing problems, teachers can evaluate the quality of different essay at the same time, so that students are more likely to help students achieve progress in writing. After the completion of the evaluation, each group can exchange the first draft, and according to the evaluation criteria for the first draft to discuss and modify, and finally complete the writing. In this part, in order to enable students to write in the language of expression more accurate and fluent, teachers can also give students some problems grammar exercises in order to enhance students 'writing ability while strengthen the students' grammar.

\section{Acknowledgements}

Xijing University Teaching Reform Research Project (JGYB1540)

\section{References}

[1] Raimes, A. Why write? Form purpose to pedagogy [J]. English Teaching Forum, 1987, 25 (4): 36-41.

[2] Raimes, A. Out of the woods: emerging traditions in the teaching of writing [J]. TESOL quarterly, 1991, 25: 407-430.

[3] Schwartz, B. D. Explicit and Negative Data Effecting and Affecting Competence andLinguistic Behavior [J]. Studies in Second Language Acquisiton, 1993

[4] Swain, M. Communicative Competence: Some roles of Comprehensible Input and Comprehensible Output in its Development [A]. In S. Gass \& C. Madden (eds). Input in Second Language acquisition. Rowley, Mass: MA: Newbery House, 1985

[5] Willis, J. A. Framework for Task-based Language Learning [M]. London: Longman Publish House, 1996 